\title{
An Update on Chemical Constituents from Nicotiana tabacum L. and Their Bioactivities from 2017 to 2020
}

\author{
Kuo Xu, ${ }^{a}$ Qian Liu, ${ }^{a}$ Lin Ni, ${ }^{b}$ Yong-Mei Du, ${ }^{* a}$ and Zhong-Feng Zhang ${ }^{*, a}$ \\ ${ }^{a}$ Tobacco Research Institute of Chinese Academy of Agricultural Sciences, Qingdao, Shandong 266101, China \\ ${ }^{b}$ Key Laboratory of Biopesticide and Chemical Biology, Ministry of Education, Fujian Agriculture and \\ Forestry University, Fuzhou, Fujian 350002, China
}

Email: zhangzhongfeng@caas.cn (Z. Z), duyongmei@cass.cn (Y. D.)

\begin{abstract}
Nicotiana tabacum L., well known as tobacco, could be not only used for raw materials of producing cigarettes, but also as a folk Chinese herbal medicine. This paper offers a systematic review of newly reported compounds from $N$. tabacum over the past four years covering the literatures from the beginning of 2017 through the end of 2020 and describes their structural diversities and bioactivities. A total of 46 natural compounds and 42 references were updated and compiles in this review, which may be of interest to pharmacognosists and natural products chemists.
\end{abstract}

Keywords Nicotiana, tobacco, chemical constituent, bioactivities

\section{Introduction}

Nicotiana tabacum L., well known as tobacco, belongs to the genus Nicotiana of Solanaceace family and originated from the tropical Americas. ${ }^{[1]}$ As one of the most commercially-valued agricultural crops worldwide, $N$. tabacum creates a lot of tax revenues for government and increases the incomes for farmers. In addition to being raw materials for producing cigarettes, the aerial part of $N$. tabacum is also used as insecticide, sedative, diaphoretic, anesthetic and emetic agents in Chinese folklore medicine. ${ }^{[2-5]}$ Previous phytochemical researches on Nicotiana plants led to the discovery of more than 2500 compounds including sesquiterpenoids, diterpenoids, alkaloids, as well as flavonoids. ${ }^{[6-11]}$ Many of them possessed excellent pharmaceutical activities. For example, $(1 S, 2 E, 4 R, 6 R, 7 E, 11 E)$ 2,7,11-cembratriene-4,6-diol ( $\alpha$-CBD) and its C-4 epimer $(1 S, 2 E, 4 S, 6 R, 7 E, 11 E)-2,7,11$-cembratriene-4,6-diol ( $\beta$-CBD) show potent neuroprotective activities and have been registered as patent in many countries. ${ }^{[12-19]}$

Several excellent reviews on various aspects of $N$. tabacum have been published in the past ten years since $2010 .^{[20-24]}$ Of these, only one has been specifically focused on the chemical constituents and their medicinal applications. In 2017, Jassbi et al. described alkaloids, aromatic compounds, flavonoids, volatiles, sesquiterpenoids, diterpenes alcohols, sugar esters, as well as acyclic hydroxygeranyllinalool diterpene glycosides from different Nicotiana species growing around the globe, emphasizing their bioactivities and functions as they have been determined either in bioassay guided purification approaches or in bioassays with plants, in which the expression of specific biosynthetic genes has been genetically manipulated. ${ }^{[24]}$ Over the past years, more interesting compounds have been identified from the crude extract of $N$. tabacum. Herein, we offer a systematic review of newly reported compounds from $N$. tabacum over the past four years covering the literatures from the beginning of 2017 through the end of 2020 and describe their structural diversities and bioactivities.

\section{Literature Search}

The literature search was performed using a previously reported method. ${ }^{[25-28]}$ The selection of the original articles was of utmost importance because these papers have a direct impact on the findings and the final results. The present review contains all original articles registered with the target subject in the "All Databases" between 2017 and 2020. The search strategy is described below:

Database: All Databases

Title: (from Nicotiana tabacum) or (of Nicotiana tabacum)

Timespan: 2017-2020

It should be noted that this review was preliminarily planned in October, 2020. The studies published or being submitted in the current year might not be indexed in Web of Science in a timely manner. Based on the aforementioned approach, 494 records were finally identified. To the best of our knowledge, these publications can be considered to cover most of the related research. After retrieving the records that were related to the field of natural product chemistry, 12 original articles were indexed over a period of four years from the beginning of 2017 to the end of 2020.

\section{Chemical Constituents}

The previous chemical investigations of $N$. tabacum indicated that 46 isolated compounds could be divided into nine categories: diterpenoids $(\mathbf{1}-\mathbf{6})$, sesquiterpenes (7-13), furan-2-carboxylic acids (14-22), flavonoids (23-32), sterols (33-36), 2-arylbenzofurans $(37,38)$, isobenzofurans $(39-41)$, phenylpropanoids (42-45), and aminoglucoside (46). Among them, terpenes and flavonoids were predominant (Figure 1).

Cembranoid is one of the characteristic chemical constituent of $N$. tabacum featured with four isoprene units in the parent skeleton of a 14-membered ring. ${ }^{[29]}$ These ingredients are present in not only the plants belonging to the genera Nicotiana and Pinus, but also marine organisms (e.g., soft coral). ${ }^{[30]}$ In the continuous searches for active compounds from $N$. tabacum, 

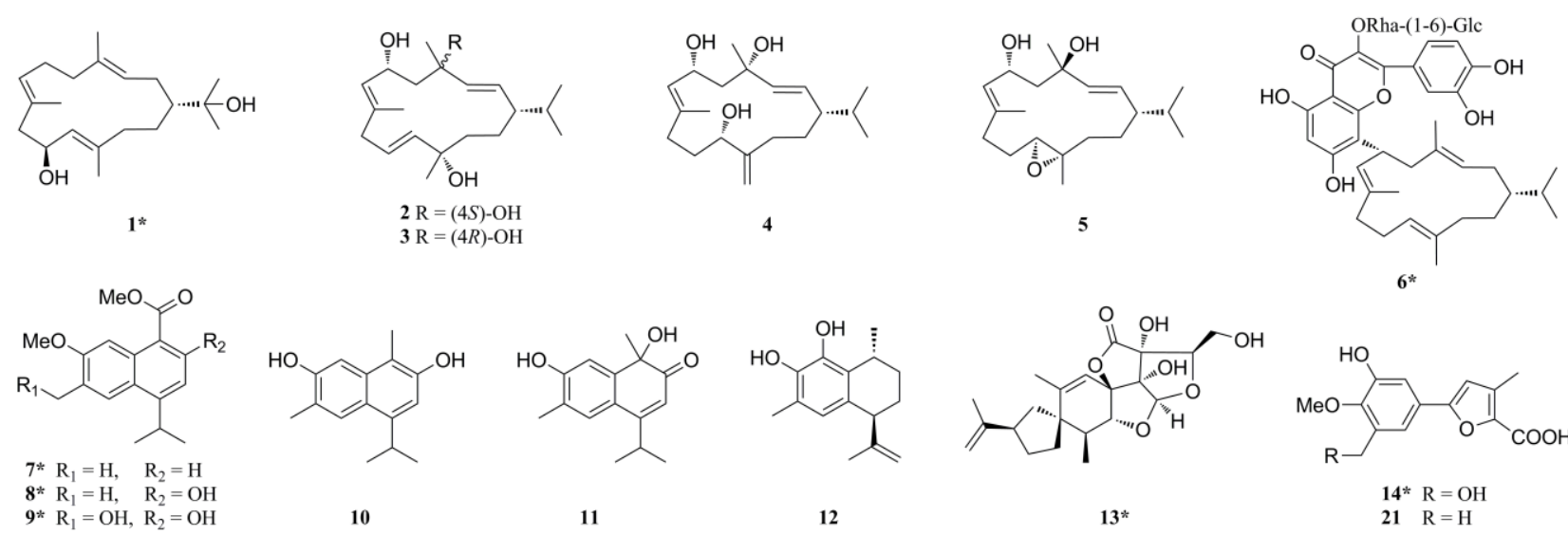

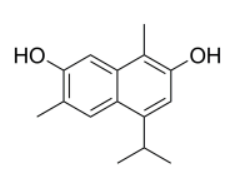<smiles>Cc1cc2c(C(C)C)cc(O)c(C)c2cc1O</smiles>

11

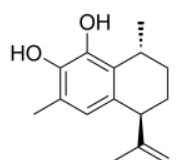

12

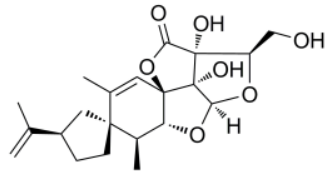

$13^{*}$

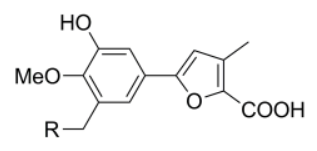

14* $\mathrm{R}=\mathrm{OH}$ $21 \quad \mathrm{R}=\mathrm{H}$

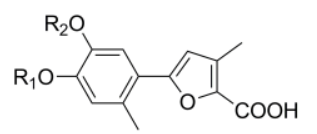

15* $\mathrm{R}_{1}=\mathrm{H}, \quad \mathrm{R}_{2}=\mathrm{CH}_{3}$ $22 \mathrm{R}_{1}=\mathrm{CH}_{3}, \mathrm{R}_{2}=\mathrm{H}$<smiles>COc1c(CCO)ccc2c(=O)cc(-c3ccccc3O)oc12</smiles>

23 *<smiles>[R6]c1cc2oc(-c3ccccc3OC)cc(=O)c2c(O)c1C</smiles>

31* $\mathrm{R}=\mathrm{H}$ 32* $\mathrm{R}=\mathrm{CH}_{3}$<smiles>COC(=O)c1oc(-c2c(C)cc(O)cc2C)cc1C</smiles>

16<smiles>Cc1cc(-c2c(C)cccc2O)oc1C(=O)O</smiles>

17<smiles>[R20]Oc1cc([R20])cc(C)c1-c1cc(CO)c(C(=O)OC)o1</smiles>

$18^{*} \mathrm{R}_{1}=\mathrm{H}, \quad \mathrm{R}_{2}=\mathrm{CH}_{3}$ $19^{*} \mathrm{R}_{1}=\mathrm{CH}_{3}, \mathrm{R}_{2}=\mathrm{H}$

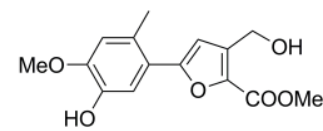

$20^{*}$<smiles>COc1c(O)cc2c(=O)cc(-c3ccc(O)cc3)oc2c1C(C)=O</smiles>

24<smiles>[R20]Oc1ccc(-c2cc(=O)c3cc(OC)c([R20])c(C(C)=O)c3o2)cc1</smiles>

25* $\mathrm{R}_{1}=\mathrm{H}, \quad \mathrm{R}_{2}=\mathrm{CH}_{3}$<smiles>COc1cc(O)c2c(c1)O[C@H](c1ccccc1)[C@H](O)C2=O</smiles>

27<smiles>[R20]Oc1c(-c2ccc(O)c([R2])c2)oc2cc(O)cc(O)c2c1=O</smiles>

$28 \mathrm{R}_{1}=\mathrm{H}, \mathrm{R}_{2}=\mathrm{OH}$ $29 \mathrm{R}_{1}=\mathrm{H}, \quad \mathrm{R}_{2}=\mathrm{H}$ $30 \mathrm{R}=$ ORha-(1-6)-Glc, $\mathrm{R}_{2}=\mathrm{OH}$

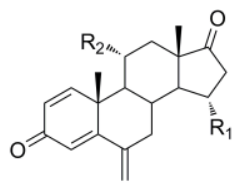

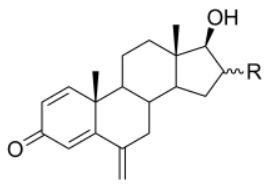<smiles>COc1ccc(-c2oc3c(C)c(C)c(C)cc3c2C)cc1</smiles><smiles>CC1(C)Oc2cc3c(cc2O1)OCCOC3</smiles><smiles>C=C(C)C(=O)Cc1cc2c(cc1O)CC(=O)OC2</smiles>

$\begin{array}{lll}\mathbf{3 3}^{*} \mathrm{R}_{1}=\mathrm{OH}, & \mathrm{R}_{2}=\mathrm{H} \\ 34 & \mathrm{R}_{1}=\mathrm{H}, & \mathrm{R}_{2}=\mathrm{OH}\end{array}$

$35 \mathrm{R}=\mathrm{H}$ $36 \mathrm{R}==\mathrm{O}$

39* $\mathrm{R}=\mathrm{H}$

$37^{*} \mathrm{R}_{1}=\mathrm{H}, \quad \mathrm{R}_{2}=\mathrm{OH}$ $\mathbf{4 0} * \mathrm{R}=\mathrm{OCH}_{3}$

41*<smiles>COc1ccc2c(c1)OC[C@@]1(O)OCOc3cc4c1cc3[C@H](O)[C@@H]2O4</smiles>

42

43<smiles>COC(=O)C1C(O)C(O)C(O)C(OC(=O)/C=C/c2ccc(O)c(O)c2)C1O</smiles>

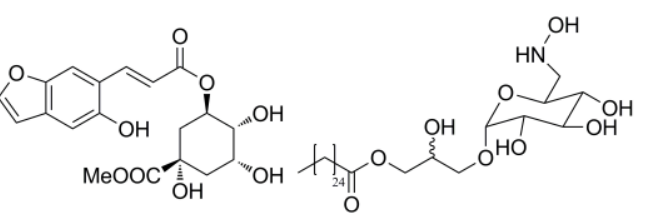

45

46

Figure 1 Chemical sturactures of compounds 1-46 ("means new compounds).

six cembranoid diterpenes $1-6$ were obtained by the silica gel and preparative HPLC. Among them, 1, 4 and 6 were reported from the leaves of $N$. tabacum for the first time. ${ }^{[31]}$ Notebly, 6 represented a novel cembrane-type diterpenoid and flavonoid heterodimer. ${ }^{[32]}$

Besides the above diterpenoids, compounds 7-13 were characterized as seven cadinane-type sesquiterpenes. Among those, compounds 7-9 were three new, while compounds 10-12 were three known compounds isolated from the stems of $N$. tabacum. ${ }^{[33]}$ Compound 13 possessed a fused 5/6/5/5/5 ring system, representing a totally new carbon skeleton of a sesquiterpenoid combined with a proposed C6 unit. ${ }^{[34]}$

Over the past four years, the researchers also found a series of furan derivatives from the stems of $N$. tabacum. Compounds 14-22 were isolated and characterized as nine furan-2-carboxylic acids. ${ }^{[35,36]}$ These compounds are an important class of secondary metabolites containing a five membered ring and holding oxygen as heteroatoms, which could be also found naturally in algae and microbe.

Flavonoid is also one of the characteristic chemical constituents of N.tabacum. Compounds 23-32 are unambiguously classified in this catalogue. ${ }^{[37-39]}$ Among them, compounds $27-30$ could be further identified as flavonol derivatives according to the substituent group at $\mathrm{C}-3$, while the others were flavones analogues. Interestingly, the latter was all C-alkylated flavones, which were rare in the extract of $N$. tabacum. Four sterols, compounds 33-36, were also isolated from the EtOAc part of an aqueous $70 \%$ acetone extract of the roots and stems of $N$. tabacum, along with the flavones 31 and 32. [39]

Both compounds $\mathbf{3 7}$ and $\mathbf{3 8}$ were identified as two new 2-arylbenzofurans derivatives, which were purified from the EtOAc part of an aqueous $95 \% \mathrm{MeOH}$ extract of the stems of 
Table 1 The names, classification, and biological activities of compounds $1-46$

\begin{tabular}{ll}
\hline No. $^{a}$ & \multicolumn{1}{c}{ Name } \\
\hline $\mathbf{1}^{*}$ & nicotiaditerpene B \\
$\mathbf{2}$ & $(1 S, 2 E, 4 S, 6 R, 7 E, 10 E, 12 S)$-2,7,10-cembratriene-4,6,11-triol \\
$\mathbf{3}$ & $(1 S, 2 E, 4 R, 6 R, 7 E, 10 E, 12 S)-2,7,10$-cembratriene-4,6,11-triol \\
$\mathbf{4}$ & $(1 S, 2 E, 4 S, 6 R, 7 E)-4,6,11$-trihydroxy-1-isopropyl-4,8-dimethylpentadeca-2,7-dien- \\
& 12-one
\end{tabular}

$5 \quad(1 S, 2 E, 4 R, 6 R, 7 E, 11 S, 12 S)$-11,12-epoxy-2,7-cembradiene-4,6-diol

6* nicotabaflavonoidglycoside

$7^{\star} \quad$ methyl 4-isopropyl-7-methoxy-6-methylnaphthalene-1-carboxylate

8* methyl 2-hydroxy-4-isopropyl-7-methoxy-6-methylnaphthalene-1-carboxylate

9* methyl 2-hydroxy-6-(hydroxymethyl)-4-isopropyl-7- methoxynaphthalene-1-carboxylate

10 2,7-dihydroxy-4-isopropyl-6-methylnaphthalene-1-carbaldehyde

11 lacinilene $\mathrm{C}$

$12(1 S, 4 R)$-7,8-dihydroxy-11,12-dehydrocalamenene

$13^{*} \quad$ nicotabin $\mathrm{A}$

$14^{\star}$

5-(3-hydroxy-5-(hydroxymethyl)-4-methoxyphenyl)-3-methylfuran-2-carboxylic acid

15* 5-(4-hydroxy-5-methoxy-2-methylphenyl)-3-methylfuran-2-carboxylic acid

31* 5,7-dihydroxy-2'-methoxy-6-methyl-flavone

32* 5-hydroxy-2',7-dimethoxy-6-methyl-flavone (8R,9S,10R,13S,14S,15S)-15-hydroxy-10,13-dimethyl-6- meth-

33* ylene-7,8,9,11,12,13,15,16-octahydro-6H-cyclopenta[a]phenanthrene-3,17(10H, $14 H)$-dione $3,17(10 H, 14 H)$-dione

34 11a-hydroxy-6-methylene-androsta-1, 4-diene-3,17-dione

35 17ß-hydroxy-6-methylen-androsta-1,4-dien-3-one

36 17ß-hydroxy-6-methylene-androsta-1,4-diene-3,16-dione

diterpenoid
diterpenoid
diterpenoid
diterpenoid
diterpenoid
diterpenoid
sesquiterpene

sesquiterpene

sesquiterpene

sesquiterpene

sesquiterpene

sesquiterpene

sesquiterpene

ran-2-carboxylic acid

-2-carboxylic acid

furan-2-carboxylic acid

furan-2-carboxylic acid

furan-2-carboxylic acid

furan-2-carboxylic acid

furan-2-carboxylic acid

furan-2-carboxylic acid

flavonoid

flavonoid

flavonoid

flavonoid

flavonoid

flavonoid

flavonoid

flavonoid

flavonoid

flavonoid

sterol

sterol

sterol

sterol
Bioactivities Ref.

No test

No test

No test

Moderate anti-TMV activity,

Moderate cytotoxicity

Potent anti-TMV activity, Moderate cytotoxicity

Potent anti-TMV activity, Moderate cytotoxicity

Moderate anti-TMV activity, Moderate cytotoxicity

Potent anti-TMV activity, Moderate cytotoxicity Moderate anti-TMV activity, Moderate cytotoxicity

Moderate anti-inflammatory activity

Moderate anti-TMV activity, Moderate cytotoxicity Moderate anti-TMV activity, Moderate cytotoxicity Moderate anti-MRSA activities, Moderate antioxidant activity

$$
\text { No test }
$$

Moderate anti-MRSA activities, Moderate antioxidant activity

Moderate anti-MRSA activities, Moderate antioxidant activity

Moderate anti-MRSA activities,

Moderate antioxidant activity

Moderate anti-MRSA activities,

Moderate antioxidant activity

Moderate anti-MRSA activities,

Moderate antioxidant activity

Potent anti-MRSA activities

Potent anti-MRSA activities

Moderate cytotoxicity

Moderate cytotoxicity

Nonsignificant cytotoxicity

Nonsignificant cytotoxicity

Nonsignificant cytotoxicity

Nonsignificant cytotoxicity potent anti-TMV activity potent anti-TMV activity

Moderate anti-TMV activity, Moderate cytotoxicity

Moderate anti-TMV activity, Moderate cytotoxicity Moderate anti-TMV activity, Nonsignificant cytotoxicity Moderate anti-TMV activity, Nonsignificant cytotoxicity 


\begin{tabular}{|c|c|c|c|c|}
\hline $37^{*}$ & 2-(4-methoxyphenyl)-3,5-dimethylbenzofuran-7-ol & 2-arylbenzofurans & $\begin{array}{c}\text { Moderate anti-TMV activity, } \\
\text { Moderate cytotoxicity }\end{array}$ & {$[40]$} \\
\hline $38^{*}$ & 2-(4-methoxyphenyl)-3,5-dimethylbenzofuran-6-ol & 2-arylbenzofurans & $\begin{array}{c}\text { Moderate anti-TMV activity, } \\
\text { Moderate cytotoxicity }\end{array}$ & [40] \\
\hline $39 *$ & 22-dimethyl-2H-furo[34-g]chromen-8(6H)-one & isobenzofurans & $\begin{array}{c}\text { Moderate anti-TMV activity, } \\
\text { Moderate cytotoxicity }\end{array}$ & [41] \\
\hline $40^{*}$ & 5-methoxy-22-dimethyl-2H-furo[34-g]chromen-8(6H)-one & isobenzofurans & $\begin{array}{c}\text { Moderate anti-TMV activity, } \\
\text { Moderate cytotoxicity }\end{array}$ & [41] \\
\hline 42 & (-)-dehydrodiconiferyl alcohol & phenylpropanoids & $\begin{array}{c}\text { Moderate anti-TMV activity, } \\
\text { Moderate cytotoxicity }\end{array}$ & [41] \\
\hline 43 & pisatin & phenylpropanoids & $\begin{array}{l}\text { Potent anti-TMV activity, } \\
\text { Moderate cytotoxicity }\end{array}$ & [41] \\
\hline 44 & turbinataphenol A & phenylpropanoids & $\begin{array}{c}\text { Potent anti-TMV activity, } \\
\text { Moderate cytotoxicity }\end{array}$ & [41] \\
\hline 46 & nicotabaamino glucoside & aminoglucoside & Weak cytotoxicity & [42] \\
\hline
\end{tabular}

${ }^{a *}$ means new compounds. ${ }^{b}$ Potent means the data was better than the positive control.

Yunyan 85 (a variety of $N$. tabacum). ${ }^{[40]}$

Compounds $\mathbf{3 9 - 4 1}$ were characterized as three new isobenzofurans, while compounds 42-45 were four known phenylpropanoids. ${ }^{[41]}$ These seven compounds were directly isolated and identified from the EtOAc part of an aqueous $70 \%$ acetone extract of the roots of Yunyan 212 (a variety of $N$. tabacum).

An ongoing investigation of natural anticancer compounds from $N$. tabacum led to the discovery of compound 46, an aminoglucoside. ${ }^{[42]}$ Its limited amount prevented the authors from testing the absolute configuration of the acyclic hydroxyl group.

\section{Bioactivities}

The bioactivities, along with the names and classifications of these isolated compounds, are shown in Table 1. The findings indicated that anti-tobacco mosaic virus (anti-TMV) activity, cytotoxicity, as well as anti-methicillin-resistant Staphylococcus aureus (anti-MRSA) activity, were the main indexes used to assess the bioactivities of these naturally occurring compounds. In this section, compounds with potent bioactivities were deliberately selected, and detailed descriptions were provided as follows.

The anti-TMV activity of compounds $7-12$ and $39-45$ at the concentration of $20 \mu \mathrm{M}$ were tested using the half-leaf method. The results showed that compounds $\mathbf{8 , 9}, \mathbf{1 1}, \mathbf{4 3}$, and 44 exhibited high anti-TMV activity with inhibition rates of $33.6 \%$, $35.8 \%, 36.7 \%, 35.1 \%$, and $33.4 \%$. The inhibition rates are even higher than that of ningnanmycin ( $2 \%$ water solution) used as a positive control. The other compounds just showed moderate anti-TMV activities with inhibition rates in the range of $22.6 \%-28.8 \%$, respectively. ${ }^{[33,41]}$ Compounds 23 and 24 exhibited good anti-MRSA activity with $\mathrm{MIC}_{90}$ value of $(38 \pm 4)$ and $(33 \pm 3) \mu \mathrm{g} / \mathrm{mL}$, respectively. However, the $\mathrm{MIC}_{90}$ value of the levofloxacin (positive control) was larger than $(56 \pm 6)$ $\mu \mathrm{g} / \mathrm{mL} .^{[37]}$

In addition to the above, compounds $\mathbf{1 - 6}$ and $\mathbf{1 7}$ were not tested for any bioactivity, while the others only showed moderate or nonsignificant bioactivities.

\section{Conclusions and Perspectives}

This review summarized a total of 46 compounds isolated from $N$. tabacum between the beginning of 2017 and the end of 2020 , of which 21 compounds were reported as new compounds and account for about $45.65 \%$. However, as one of another characteristic constituents of $N$. tabacum, the alkaloids have received less attention over the past years. Tobacco alkaloids should be one of the most challenging natural product classes to characterize, not only because of their structurally unique skeletons arising from distinct amino acids but also because of their potential bioactivities. As part of our ongoing investigations of natural antimicrobial and insecticidal lead compounds from $N$. tabacum, tobacco alkaloids will be selected for further chemical study preferentially. The bioactivities of these natural compounds are also discussed. However, it's a pity that no obvious structure-activity relationship was found.

All the original articles were identified by searching the Web of Science database, and we think these papers include most of the recently reported natural compounds from Nicotiana tabacum. However, it is unavoidable that a certain number of works might not have been retrieved based on the literature search used to compile this review.

\section{Acknowledgement}

This research was supported by the Science Foundation for Young Scholars of Tobacco Research Institute of Chinese Academy of Agricultural Sciences (No. 2020B02), the Foundation of Key Laboratory of Biopesticide and Chemical Biology, Ministry of Education, Fujian Agriculture and Forestry University (No. Keylab2019-05), the Foundation of Key Laboratory of Plant Resources Conservation and Sustainable Utilization, South China Botanical Garden, Chinese Academy of Sciences (No. PCU202001), and the Agricultural Science and Technology Innovation Program (No. ASTIP-TRIC05).

\section{Conflict of Interest}

The authors declare no conflict of interest

Copyright (c) 2020 Kuo Xu, Qian Liu, Lin Ni, Yong-Mei Du, Zhong-Feng Zhang. This article is an open access article distributed under the terms and conditions of the Creative Commons Attribution (CC BY) license (http://creativecommons.org/licenses/by/4.0/). The use, distribution or reproduction in other forums is permitted, provided the original author(s) or licensor are credited and that the original publication in this journal is cited, in accordance with accepted academic practice. No use, distribution or reproduction is permitted which does not comply with these terms. 


\section{References}

[1] China Flora Editorial Board (Chinese Academy of Sciences). Flora of China; Science Press, Beijing, 1978, 67, pp. 152-153.

[2] Yang, F. H.; Gu, H. M.; Li, J. Q. The edible and medicinal use of tobacco. Journal of Mudanjiang Medical College 1998, 19, 70-72.

[3] Fu, H. M.; Wei, H.; Liu, Z. L. Progress on herbal textual research and medicinal applications of tobacco. Journal of Pharmaceutical Practice 2005, 23, 321-325.

[4] Tian, Y. Q.; Ding, P.; Zhang, Y. Q. Overview on researches of medicinal use of tobacco. China Pharm. 2015, 24, 126-128.

[5] Ju, S. Y.; Xu, X. M.; Dai, J. G. Herbal textual studies on tobacco. Electronic Journal of Clinical Medical Literature 2020, 7, 154-155.

[6] Nugroho, L. H.; Verpoorte, R. Secondary metabolism in tobacco. Plant Cell, Tissue Organ Cult. 2002, 68, 105-125.

[7] Hakkinen, S. T. ; Tilleman, S. ; Swiatek, A. ; De Sutter, V. ; Rischer, H.; Vanhoutte, I.; Van Onckelen, H.; Hilson, P.; Inze, D.; Oksman-Caldentey, K. M.; Goossens, A. Functional characterisation of genes involved in pyridine alkaloid biosynthesis in tobacco. Phytochemistry 2007, 68, 2773-2785.

[8] Rodgman, A.; Perfetti, T. A. The Chemical Components of Tobacco and Tobacco Smoke, CRC Press, Florida, 2012, p. 10.

[9] Yang, C. Y.; Geng, C. A.; Ma, Y. B.; Huang, X. Y.; Zhang, X. M.; Zhou, J.; Chen, J. J. Two new sesquiterpenoid glycosides from Nicotiana tabacum. J. Asian Nat. Prod. Res. 2014, 16, 611-616.

[10] Sun, H. R.; Sun, M. Study on Chemical Constituents from Tobacco Leaves, International Conference on Electrical Engineering and Automation (ICEEA), 2016, pp. 700-702.

[11] Yang, P. F.; Hua, T.; Huang, S.; Yang, J.; Wei, T.; Mao, D. Progress on cembranoid diterpenes in tobacco. Chem. Reagents 2020, 42, 380-388.

[12] Eterovic, V. A.; Pérez, D.; Martins, A. H.; Cuadrado, B. L.; Carrasco, M.; Ferchmin, P. A. A cembranoid protects acute hippocampal slices against paraoxon neurotoxicity. Toxicol. In Vitro 2011, 25, 1468-1474.

[13] Ferchmin, P. A.; Andino, M.; Salaman, R. R.; Alves, J.; Velez-Roman, J.; Cuadrado, B.; Carrasco, M.; Torres-Rivera, W.; Segarra, A.; Martins, A. H.; Lee, J. E.; Eterovic, V. A. 4R-cembranoid protects against diisopropylfluorophosphatemediated neurodegeneration. Neurotoxicology 2014, 44, 80-90.

[14] Martins, A. H.; Hu, J.; Xu, Z.; Mu, C.; Alvarez, P.; Ford, B. D.; El Sayed, K.; Eterovic, V. A.; Ferchmin, P. A.; Hao, J. Neuroprotective activity of $(1 S, 2 E, 4 R, 6 R, 7 E, 11 E)$-2,7,11-cembratriene-4,6-diol ( $4 R)$ in vitro and in vivo in rodent models of brain ischemia. Neuroscience 2015, 291, 250-259.

[15] Hu, J.; Ferchmin, P. A.; Hemmerle, A. M.; Seroogy, K. B.; Eterovic, V. A.; Hao, J. 4R-cembranoid improves outcomes after 6-hydroxydopamine challenge in both in vitro and in vivo models of Parkinson's disease. Front. Neurosci. 2017, 11, 272-283.

[16] Eterovic, V. A.; Ferchmin, P. A.; Hann, R. M.; Pagan, O. R.; Rodriguez, A. D.; Rosario, O. Tobacco cembranoids block the expression of the behavioral sensitization to nicotine and inhibit neuronal acetylcholine receptors. US 6,489, 357 B1, 2002

[17] Ferchmin, P. A.; Eterovic, V. A.; Maldonado, H. M. Neuronal circuit-dependent neuroprotection by interaction between nicotinic receptors. WO 2008/002594 A2, 2008.

[18] Eterovic, V. A.; Rodriguez, A. D.; Hann, R. M.; Ferchmin, P. A.; Pagan, O. R. Cembranoid inhibitors of nicotinic acetylcholine receptors. WO 98/55111, 1998.

[19] Ford, B. D.; Ferchmin, P. A.; Eterovic, V. A. Methods and compositions for protecting and treating neuroinjury. US 2011/0015186 A1, 2011

[20] Lugon-Moulin, N.; Zhang, M.; Gadani, F.; Rossi, L.; Koller, D.; Krauss, M.; Wagner, GJ. Critical review of the science and options for reducing cadmium in tobacco (Nicotiana Tabacum L. ) and other plants. Adv. Agron. 2004, 83, 111-180.

[21] Certal, A. C.; Almeida, R. B.; Carvalho, L. M.; Wong, E.; Moreno, N.;
Michard, E.; Carneiro, J.; Rodriguez-Leon, J.; Wu, H. M.; Cheung, A. Y.; Feijo, J. A. Exclusion of a proton ATPase from the apical membrane is associated with cell polarity and tip growth in Nicotiana tabacum pollen tubes. Plant Cell 2008, 20, 614-634.

[22] Chen, S.; Liu, GS.; Wang, YY.; Sun, YH.; Chen, J. Cloning of a calcium-dependent protein kinase gene NtCDPK12, and its induced expression by high-salt and drought in Nicotiana tabacum. Agric. Sci. China 2011, 10, 1851-1860

[23] Dewey, R. E.; Xie, J. H. Molecular genetics of alkaloid biosynthesis in Nicotiana tabacum. Phytochemistry 2013, 94, 10-27.

[24] Jassbi, A. R.; Zare, S.; Asadollahi, M.; Schuman, M. C. Ecological roles and biological activities of specialized metabolites from the genus Nicotiana. Chem. Rev. 2017, 117, 12227-12280.

[25] Soosaraei, M.; Khasseh, A. A.; Fakhar, M.; Hezarjaribi, H. Z. A decade bibliometric analysis of global research on leishmaniasis in Web of Science database. Ann. Med. Surg. 2018, 26, 30-37.

[26] Chang, H. T.; Lin, M. H.; Hwang, I. H.; Chen, T. J.; Lin, H. C.; Hou, M. C.; Hwang, S. J. Scientific publications in gastroenterology and hepatology in Taiwan: An analysis of Web of Science from 1993 to 2013. J. Chin. Med. Assoc. 2017, 80, 80-85.

[27] Zhang, P.; Wei, Q.; Yuan, X. L.; Xu, K. Newly reported alkaloids produced by marine-derived Penicillium species (covering 2014-2018). Bioorg. Chem. 2020, 99, 103840-103853.

[28] Xu, K.; Yuan, X. L.; Li, C.; Li, X. D. Recent Discovery of Heterocyclic Alkaloids from Marine-Derived Aspergillus Species. Mar. Drugs 2020, 18, 54-75.

[29] Yan, N.; Du, Y.; Liu, X.; Zhang, H.; Liu, Y.; Zhang, Z. A review on bioactivities of tobacco cembranoid diterpenes. Biomolecules 2019, 9, 30-38.

[30] Liu, X.; Zhang, J.; Liu, Q.; Tang, G.; Wang, H.; Fan, C.; Yin, S. Bioactive cembranoids from the South China Sea soft coral Sarcophyton elegans. Molecules 2015, 20, 13324-13335.

[31] Zheng, Q. X.; Liu, P. P.; Zhai, N.; Chen, Q. S.; Jin, L. F.; Chen, X.; Zhou, H. N. A new diterpene from leaves of Nicotiana tabacum. Chin. Tradit. Herb. Drugs 2017, 48, 2597-2600

[32] Yang, C. Y.; Lin, Y.; Yuan, H. X.; Yang, W. P.; Xian, W.; Huang, Z. L. Nicotabaflavonoidglycoside, the first example of cembranoid and flavonoid heterodimer from Nicotiana tabacum. Fitoterapia 2018, 128, 242-246.

[33] Yang, P. S.; Tang, S. Y.; Liu, C. B.; Ye, L.; Zhang, F. M.; He, P.; Liu, Z. H.; Chen, Y. K.; Miao, M. M.; Shen, Q. P.; Wang J. Q. Three new sesquiterpenes from the stems of Nicotiana tabacum and their bioactivities. J. Asian Nat. Prod. Res. 2019, 21, 109-116.

[34] Feng, T.; Li, X. M.; He, J.; Ai, H. L.; Chen, H. P.; Li, X. N.; Li, Z. H.; Liu, J. K. Nicotabin A, a sesquiterpenoid derivative from Nicotiana tabacum. Org. Lett. 2017, 19, 5201-5203.

[35] Wu, Y. P.; Kong, G. H.; Li, W.; Ye, L.; Tang, D. Y.; Zhang, F. M.; He P.; Liu, Z.H.; Shen, Q. P.; Xia, Z. Y.; Liu, C.B. Furan-2-carboxylic acids from the roots of Nicotiana tabacum and their bioactivities Chem. Nat. Compd. 2018, 54, 270-273.

[36] Li, Y.K.; Lv, N.; Luo, D.; Kong, W. S.; Mi, Q. L.; Gao, Q.; Zeng, W. L.; Li, J.; Ling, J.; Liu, C. B.; Yang, G. Y.; Li, X. M.; Chen, Z. Y.; Hu, Q. F. Three new furan-2-carboxylic acid derivatives from the stem bark of Nicotiana tabacum and their bioactivity. Heterocycles 2020, 100, 267-275.

[37] Wu, Y. P.; Li, X. M.; Kong, W. S.; Geng, Y. Q.; Liu, X.; Du, G.; Yang H. Y.; Li, J.; Hu, Q. F. A new flavone from leaves of Nicotiana tabacum and its antibacterial activity. Chin. Tradit. Herb. Drugs 2018, 49, 5238-5241.

[38] Chien, S. K.; Chen, L. C.; Huang, H. C.; Chen, L. C.; Hsiao, J. W.; Cheng, M. J.; Chen, J. J. A new flavone and cytotoxic constituents of Nicotiana tabacum. Chem. Nat. Compd. 2018, 54, 1044-1047.

[39] Shang, S.; Shi, J.; Tang, J.; Jiang, J.; Zhao, W.; Zheng, X.; Lei, P.; Han, J.; Wang, C.; Yuan, D.; Yang, G.; Chen, Y.; Miao, M. New isolates from leaves of Nicotiana tabacum and their biological activities. Nat. Prod. Res. 2019, 33, 1577-1583.

[40] Xu, X.; Shi, J.; Li, C.; Zhang, W.; Shen, X.; Ma, X.; Chen, W.; Deng, 
L.; Li, X. M.; Guo, Y. Two new 2-arylbenzofurans from the stems of Nicotiana tabacum and their bioactivities. Chem. Nat. Compd. 2017, 53, 883-886.

[41] He, P.; Yang, P.; Tang, S.; Ye, L.; Liu, C.; Shen, Q.; Tang, D.; Zhang, F.; Liu, Z.; Chen, Y.; Yao, S.; Xiang, N.; Huan, Z. Three new isobenzofurans from the roots of Nicotiana tabacum and their bioactivities. Nat. Prod. Res. 2017, 31, 2730-2736.
[42] Yang, C. Y.; Yuan, H. X.; Pan, Q. D.; Huang, Y. H.; Yang, W. P. Huang, Z. L. One new aminoglucoside compound from the leaves of Nicotiana tabacum. Nat. Prod. Res. Dev. 2019, 31, 455-458.

Received November 13, 2020 Accepted December 4, 2020 